Provided for non-commercial research and education use. Not for reproduction, distribution or commercial use.

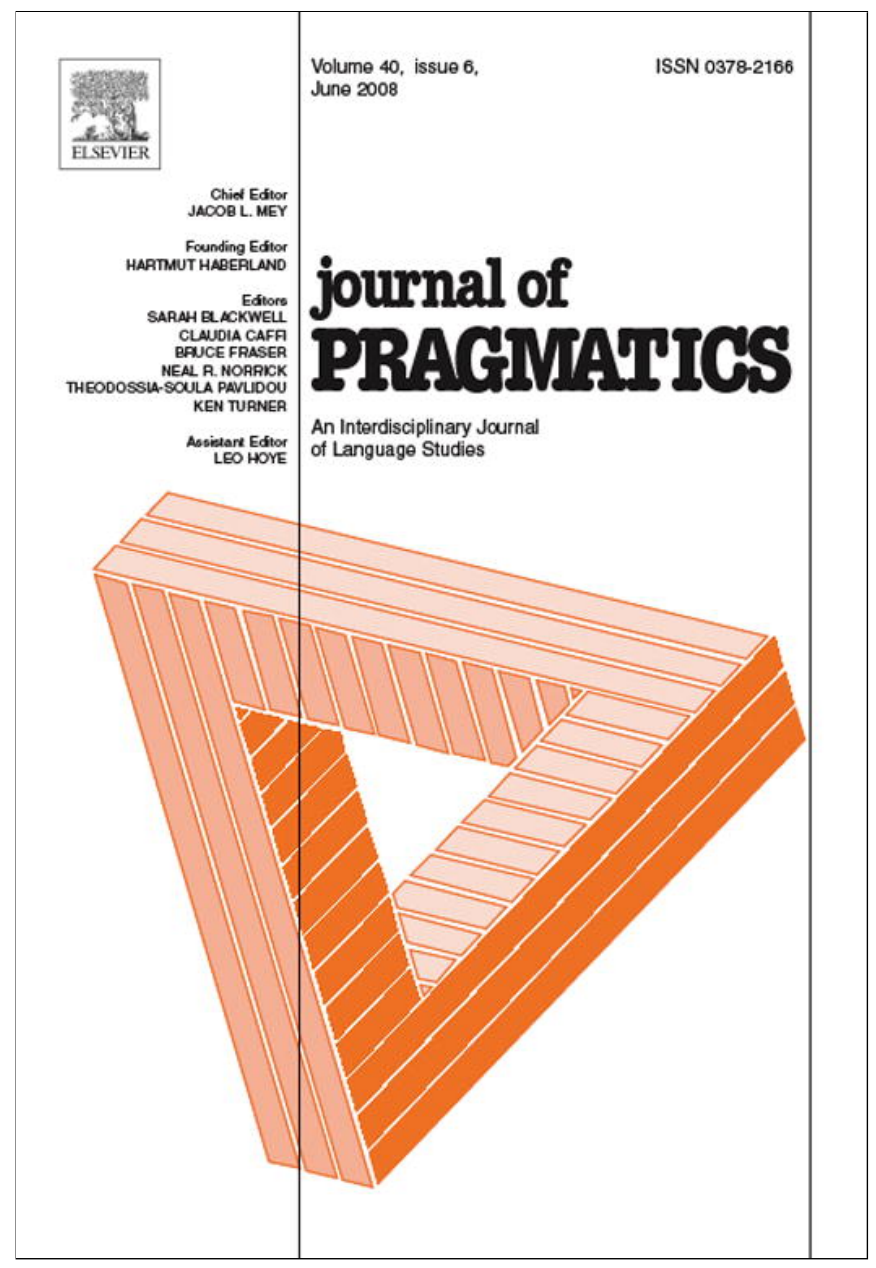

This article appeared in a journal published by Elsevier. The attached copy is furnished to the author for internal non-commercial research and education use, including for instruction at the authors institution and sharing with colleagues.

Other uses, including reproduction and distribution, or selling or licensing copies, or posting to personal, institutional or third party websites are prohibited.

In most cases authors are permitted to post their version of the article (e.g. in Word or Tex form) to their personal website or institutional repository. Authors requiring further information regarding Elsevier's archiving and manuscript policies are encouraged to visit:

http://www.elsevier.com/copyright 


\title{
Belief reports and pragmatic intrusion (the case of null appositives)
}

\author{
Alessandro Capone \\ Department of Philosophy, University of Palermo, Via Francesco P 105, 98051 Barcelona (ME), Italy \\ Received 10 February 2006; received in revised form 15 February 2008; accepted 24 February 2008
}

\begin{abstract}
In this paper, I explore Bach's idea (Bach, 2000) that null appositives, intended as expanded qua-clauses, can resolve the puzzles of belief reports. These puzzles are crucial in understanding the semantics and pragmatics of belief reports and are presented in a section. I propose that Bach's strategy is not only a way of dealing with puzzles, but also an ideal way of dealing with belief reports. I argue that even simple unproblematic cases of belief reports are cases of pragmatic intrusion, involving null appositives, or to use the words of Bach, 'qua-clauses'. The main difference between my pragmatic approach and the one by Salmon (1986) is that this author uses the notion of conversational implicature, whereas I use the notion of pragmatic intrusion and explicature. From my point of view, statements such as "John believes that Cicero is clever" and "John believes that Tully is clever" have got distinct truth-values. In other words, I claim that belief reports in the default case illuminate the hearer on the mental life of the believer, that includes specific modes of presentation of the referents talked about. Furthermore, while in the other pragmatic approaches, it is mysterious how a mode of presentation is assumed to be the main filter of the believer's mental life, here I provide an explanatory account in terms of relevance, cognitive effects, and processing efforts. The most important part of the paper is devoted to showing that null appositives are required, in the case of belief reports, to explain certain anaphoric effects, which would otherwise be mysterious. My examples show that null appositives are not necessitated at logical form, but only at the level of the explicature, in line with the standard assumptions by Carston and Recanati on pragmatic intrusion. I develop a potentially useful analysis of belief reports by exploiting syntactic and semantic considerations on presuppositional clitics in Romance.
\end{abstract}

(C) 2008 Elsevier B.V. All rights reserved.

Keywords: Belief reports; Propositional attitudes; Pragmatic intrusion null appositives

E-mail address: alessandro.capone@istruzione.it. 
Deus illuminatio mea.

As Mey (2001) says:

Pragmatics admonishes the linguistic scientists that they should take the users of language more seriously, as they, after all, provide the bread and butter of linguistic theorizing (...) (Mey, 2001:289).

It is in the spirit of this view that I submit a paper on belief reports and pragmatic intrusion. In this paper, I discuss belief reports such as "John believes that Mary is in Paris". I propose to integrate the treatment of belief reports with the recent idea (mainly propounded by relevance theorists such as Carston, 2002 and Sperber and Wilson, 2002, but also, in different form, by Bach, 1994; Levinson, 2000; and Mey, 2001) that the proposition expressed by an utterance (in a context C) is ultimately fleshed out (supplied on the basis of a skeletal semantic template, to use words by Carston) by recourse to pragmatics, which constructs missing constituents or expands the bare semantics of a sentence to resolve potential inconsistencies or absurdities. In particular, I propose that belief reports are cases of "intrusive constructions" (to use a term by Levinson, 2000:213), in that the truth-conditions of the whole depend on a pragmatic process of interpretation. My treatment regards modes of presentation as implicit appositives. The proposal I articulate in this article assumes that verbs like 'believe' (attitudinatives, to use a term by Green, 1998) are semantically univocal and not ambiguous. It appears to me that by placing the burden of providing modes of presentation on pragmatics we can abide by Modified Occam's Razor, which advises us not to multiply senses without necessity.

\section{Pragmatic intrusion}

Many authors have dealt with the semantics/pragmatics debate, but here I shall mainly expose ideas by Carston (1999) and Wilson and Sperber (2002). The reader will find an overview of other theories in Capone (2006a). Here I cannot deal adequately with the views of Bach (1994), Levinson (2000) (see my review), Recanati (2004) (see my review) and of Stainton (2004a,b), which are also important.

Below are some of the examples relevance theorists use in support of the case for pragmatic intrusion:

(1) The steak is raw;

(2) Holland is flat;

(3) Jane is a bulldozer;

(4) He took off his boots and got into bed;

(5) Writing an essay will take time;

(6) Everyone went to the party.

(1) Is true even if the steak is not completely raw, but only partially cooked; (2) is true even if Holland's surface is not, strictly speaking, completely flat but is flatter than most other European countries; (3) is obviously false, and thus a metaphoric interpretation must be accessed to consider it true; (4) is true in case the action of taking the boots off precedes the action of going into bed; (5) does not express the trivial proposition that writing an essay takes some time, but that it takes a considerable amount of time (and attention); (6) obviously does not mean that all 
human beings went to the party, but that all members of a certain domain went to the party; thus the domain of the quantifier must be suitably restricted by means of contextual knowledge.

\section{Puzzles arising from belief reports}

The puzzles of belief reports constitute an area where pragmatics has interesting and promising applications. Consider Kripke's puzzle. The author presents the case of Pierre, a French speaker, who, on the basis of what he hears about London, says "Londres est jolie", leading us to conclude that he believes that London is pretty. However, one day Pierre moves to London and goes to live in a rather ugly area of the city. He learns English without resorting to translation and is now willing to assent to the sentence "London is not pretty". He is not in a position to equate what he thought of under the name 'Londres' with what he now thinks of under the name 'London' (Kripke, 1979:891892). Kripke rejects the idea that Pierre has got contradictory beliefs; He says that Pierre lacks information, not logical acumen, and thus he is not able to grasp that his notion of 'Londres' and his notion of 'London' are two notions of one and the same thing.

There is another puzzle, which according to Kripke (1979), arises without substitution. Consider the following utterances proffered in a context in which both the speaker and the hearer know that Paderewski is both statesman and pianist:

(7) Peter believes that Paderewski had musical talent.

(8) Peter disbelieves that Paderewski had musical talent.

Peter uses the name 'Paderewski' for what he takes to be two different individuals. The problem is to explain, given that Peter does not realize that Paderewski the statesman is Paderewski the pianist, how both of (7) and (8) can be true. It may appear that Peter has contradictory beliefs, but this is not the case. Peter is not illogical, he is merely ignorant.

Crimmins and Perry (1989) resolve problems of this kind by noting that the same referent can be associated with two different notions and that failure to connect these notions leads a person to be in two distinct belief states. The most important idea of their paper is that a belief report can involve an unarticulated constituent specifying a mode of presentation. Context is what leads to the specification of this constituent.

\section{Bach's view of belief reports}

Let us now return to the issue of belief reports, armed with the notion that pragmatic intrusion furnishes a fully truth-evaluable proposition.

Bach's view of belief reports is one such theory. Bach says that even though 'that'-clauses express propositions, belief reports do not in general specify things that people believe (or disbelieve) - they merely describe or characterize them (Bach, 2000:121). Bach stresses the role played by pragmatic intrusion in fleshing out the proposition believed on the basis of the surface elements appearing in the 'that'-clause and the context which serves to enrich or expand the proposition.

Let us see how this approach allows us to handle the Paderewski case. Let us recall that the problem arises due to ignorance: Peter has two notions of Paderewski, which, as Crimmins and Perry say, he is not able to connect, in other words he does not think they are two notions of one and the same thing. Peter believes of Paderewski, of whom he knows that he is a musician, that he has musical talent. And he believes of Paderewski, of whom he knows that he is a statesman, that 
he has no musical talent. Peter is not able to grasp that the two notions are notions of one and the same thing as he is ignorant of the fact that Paderewski the statesman is nothing but Paderewski the musician. Thus, we can say of Peter both (9) and (10):

(9) Peter believes that Paderewski had musical talent;

(10) Peter disbelieves that Paderewski had musical talent (understood as: Peter believes that Paderewski had no musical talent).

(9) and (10) do not attribute contradictory beliefs to Peter - even if the speaker of (9) and (10) knows that there is a referential identity between the two instances of 'Paderewski' - provided that Peter is not able to grasp that the two notions he has of Paderewski are notions of one and the same thing.

Bach explains why (9) and (10) are not contradictory statements by saying that the 'that'-clauses do not fully specify the propositions believed (by Peter), but simply characterize them. To fully specify what Peter believes in the two cases, we need to flesh out the proposition corresponding to the 'that'-clause, using appositives both in (9) and (10), thus obtaining (11) and (12):

(11) Peter believes that Paderewski, the pianist, had musical talent;

Peter disbelieves that Paderewski, the statesman, had musical talent.

Bach writes about examples (11) and (12):

This difference could be indicated by using the appositives 'the pianist' and 'the statesman' after the name 'Paderewski'. Using one appositive rather than the other would be sufficient, in the context, to differentiate one belief from the other, although both beliefs are such as to be true only if Paderewski had musical talent (Bach, 2000:126). ${ }^{1}$

Bach's proposal is a step forward towards a theory of belief reports. He proposes to make modes of presentation of the referent 'Paderewski' explicit. Bach's idea that an appositive qua-clause is supplied by pragmatics in utterances such as (11) and (12) is shared by Bezuidenhout (2000). Like Bach (2000), she too claims that this process of inferential enrichment is the norm, rather than an 'ad hoc' way of resolving a puzzle. Bach's idea that modes of presentation must be made explicit in order to deal with Paderewski-like cases is important. Yet, something else has to be said.

First, (11) and (12) are interpretatively ambiguous: on one interpretation the appositive specifies how Peter thinks of Paderewski; on the other, it specifies who the speaker of the entire sentence has in mind. So (11) and (12) are simply not the interpretations of (9) and (10). ${ }^{2}$

Secondly, the fact that Peter has two different notions of Paderewski, as is known in context, does not suffice to make his two beliefs about the two notions of Paderewski's non-contradictory. Suppose, in fact, that at some stage he thought that the two notions of Paderewski are notions of one and the same individual (and this realization can be grasped pragmatically by using further

\footnotetext{
${ }^{1}$ A referee notes that something is missing in the quotation above. However I checked again and the quotation is accurate. Bach also insists (personal communication) that the quotation is accurate. It appears to me too that some words are missing such as "Using one appositive rather than the other would be sufficient, in the context, to differentiate one belief from the other, although both beliefs are such as to be true only if Peter believes Paderewski had musical talent".

${ }^{2}$ Surely one might say this problem can be resolved by devising unambiguous notation. Of course, part of the problem lies in finding appropriate unambiguous notation, yet the focus of this paper is how we arrive at such interpretations. Presumably such an unambiguous notation involves anchoring the MoP to either the speaker or the believer: thus one could use the unambiguous representations: $\operatorname{MoP}(\mathrm{s}), \operatorname{MoP}(\mathrm{b})$.
} 
appositives). Then, at least for a moment, he must have had contradictory thoughts contemplating the thoughts (19) and (20). So, the 'that'-clauses must be specified further and the inexplicit hidden constituents to be fleshed out must include Paderewski, the pianist, an individual distinct from Paderewski, the statesman.

The most interesting part of the theory is that it is applicable to all substitution cases, as well. Thus, in principle it ought to explain why is it that a speaker can say both of:

(13) Alexander believes that Cicero was a great orator of the past;

(14) Alexander does not believe that Tullius was a great orator of the past

provided that it is part of contextual knowledge that Alexander does not know that Cicero is also known under the mode of presentation 'Tullius'.

Bach does not go to great length to explain how pragmatic intrusion can account for examples such as (13) and (14). Intuitively, it is clear that what makes the two statements non-contradictory is the fact that Alexander is not able to grasp that his two notions 'Cicero' and 'Tullius' are notions of one and the same thing. Now, pairs of sentences such as (13) and (14) must always be evaluated in context, where contextual knowledge provides conceptual material that serves to expand the that-clauses further and make it clear that the notions 'Cicero' and 'Tullius' are not linked. The missing constituent is something like (15) or (16):

(15) the great orator;

(16) the man I bumped into yesterday at the market place.

\section{On modes of presentation again (pragmatic intrusion)}

It is time to explain opacity phenomena and the puzzles associated with belief reports through a theory of pragmatic intrusion in which modes of presentation of propositions are supplied through pragmatics.

Consider a sentence such as (17):

John believes that Mary Smith is clever.

Suppose that the referent of 'Mary Smith' is $x$; then it would be reasonable to assume that if (17) is true, John must believe of $x$, under the mode of presentation 'Mary Smith', that she is clever. For Salmon (1986) (18) expresses the same proposition as (19):

(18) John believes that she is clever;

(19) John believes that Mary Smith is clever.

He explains the fact that an ordinary speaker may judge that (18) and (19) have distinct truthvalues by resorting to a Gricean pragmatic reasoning. If a speaker attributes the pronominal mode of presentation 'she' to John, it would be misleading to use a more informative sentence such as (19), which leads the hearer to attribute the mode of presentation 'Mary Smith' to John. Thus, it is not really reasonable to trust the judgements of ordinary speakers, who cannot distinguish between truth-conditional and non-truth-conditional elements of meaning.

In this paper I will recast Salmon's pragmatic view in terms of relevance theory.

Consider a simple sentence such as (20): 
(20) has the following logical form:

John believes of $x$ that she is clever.Pragmatics adds the constituent: under mode of presentation MoP/Mary Smith. Thus, via pragmatic intrusion, we have: John believes of $x$, under MoP, that she is clever. A more elegant representation of this interpretation is certainly the following, adapted from Green (1998):

BEL [John, that Mary Smith is clever, ft (John, 'Mary Smith is clever')]

where $\mathrm{ft}(x, S)$ is a function that takes a person $x$, a sentence $S$ and a time argument $t$ as arguments and gives as values the way $x$ would take the information content of sentence $S$, at $t$, were it presented to him or her through the very sentence $S$.

I now try to provide an explanation of the interpretation of belief reports on the basis of Sperber and Wilson's relevance theory (Sperber and Wilson, 1986). The principle at work in the pragmatic specification of modes of presentation is the following:

Communicative principle of relevance. According to this principle, every act of ostensive communication communicates a presumption of its optimal relevance. An ostensive stimulus is optimally relevant if it is (a) relevant enough to be worth the hearer's attention; (b) the most relevant stimulus the speaker could have produced given her abilities and preferences (Sperber and Wilson, 1995:270).

The sentence (20) is optimally relevant if the NP 'Mary Smith' is the mode of presentation associated (pragmatically) with the referent of 'Mary Smith', in other words if it plays some role in the identification of reference for the believer. Given that relevance is a ratio of contextual effects and cognitive efforts, it goes without saying that either cognitive efforts or cognitive efforts play a role in the calculation of relevance. I propose that the interpretation that is most relevant is the one in which the MoP 'Mary Smith' is actually used by the believer in identifying the referent in question. All one needs explaining is why the assumption that 'Mary Smith' is a MoP for the believer under which he holds the proposition has greater relevance than the assumption that the believer holds the same proposition under a different MoP. Suppose the hearer does not content herself with the assumption that "Mary Smith" is the MoP under which the belief is held; then she ought to search for some other MoP, presumably relying on contextual assumptions. However, suppose the context does not provide any alternative MoP or provides too many candidates for the actual MoP under which the belief is held. Then surely searching for alternative MoPs when one is already used in the sentence looks like a vane expenditure of processing efforts. Relevance, which is an inverse function of processing costs, would dramatically decrease. Even if a plausible alternative MoP were to be found, one would have to ask oneself why the speaker actually meant a mode of presentation distinct from the one that is present in the complement clause of the belief report in order to inform the hearer about the believer's mental state. The only context in which the processing costs would not make the interpretation less relevant would be one in which the positive effects outweigh the processing costs.

Now we can explain in a more articulated manner why we have the intuition that (18) and (19) do not have the same truth-conditions, given that we accept that pragmatic intrusion contributes to a fully truth-evaluable proposition (e.g. Carston, 1999) and, thus, is part of what is said (according to Carston's (2002) notion of what is said, not according to Bach's notion of what is said; on the distinction see Burton-Roberts, 2005; and Burton-Roberts, 2006). If my ideas are 
correct, the fact that (18) and (19) intuitively have got distinct truth-conditions (ordinary speakers would perceive them to have distinct truth-conditions, regardless of how things are from a theoretical point of view) is merely the consequence of our theoretical assumptions that pragmatics contributes to the proposition expressed. My ideas are in line with Sperber and Wilson's view of explicitness outlined in Relevance (1986:182):

Explicitness:

An assumption communicated by an utterance $U$ is explicit if and only if it is a development of a logical form encoded by $U$.

On the analogy of 'implicature', Sperber and Wilson call an explicitly communicated assumption an explicature. Logical forms are 'developed' into explicatures by inferential enrichment. Every explicature, then, is recovered by a combination of decoding and inference.

The picture we have come to is somewhat different from that adopted in other pragmatic views of propositional attitudes. Salmon (1986) would say that the sentences (18) and (19) have got the same truth-conditions, because he essentially leaves pragmatic intrusion out of the picture. Or, to be more precise, he allows pragmatic intrusion up to a point, until the referents of 'she' and 'Mary Smith' are made part of the interpreted logical form, but does not accept (at least not explicitly) a more radically intrusionistic view, like the one I proposed along the lines of Carston (1999) or Wilson and Sperber (2002), in which the provision of modes of presentation is made part of the proposition uttered. Consider (21) and (22):

\section{John believes that Hesperus is Hesperus;} John believes that Hesperus is Phosphorus.

Ordinary speakers appear to attribute distinct truth-conditions to these statements. Salmon explains the oddity in such a judgement by saying that it would be misleading for a speaker who commits herself to (21) to utter (22), since the reference to a mode of presentation (of the reference) is part of the pragmatics of the belief report.

Unlike Salmon, I adopt a fully intrusionistic picture in line with Carston (1999) and Wilson and Sperber (2002), and say that the propositions which John is said to believe in (21) and in (22) are distinct, as they include distinct modes of presentation. The pragmatic machinery is responsible for the fleshing out of the propositions believed and the inclusion there of distinct modes of presentation.

We have to consider a natural objection arising from accepting Devitt (1996). In my view, a speaker who utters (23):

John believes that Mary is pretty

normally ascribes a belief to John and the NP used in the embedded sentence furnishes the mode of presentation under which John's belief is held.

A natural objection to the considerations above is that an utterance of (24):

John believes that Mary Smith is pretty,

can be interpreted without having to assume that 'Mary Smith' is a mode of presentation under which the belief is held. After all, as Devitt (1996) says, the NP could be used to facilitate 
recognition of the referent to the hearer of the belief report, in which case it need not play a crucial role in the mental life of the believer (John).

Now, I do not deny that there might be a context in which the hearer $\mathrm{H}$, faced with (24), replies: "Sorry, I do not know Mary Smith", and then the speaker replaces (24) with (25):

John believes that [our department's secretary] 0 is pretty.

In this case, given that the context is different, and that the hearer understands that the correction has been made to enhance the hearer's comprehension, optimal relevance is achieved if 'our department's secretary' is not the mode of presentation under which the belief is presented (to the believer). In a context in which the focus is on action, the greater processing efforts involved by failing to use the subject NP of the embedded clause to specify John's belief are balanced by the greater cognitive effects achieved if one uses descriptions which facilitate the action in question. The practical concerns which lie at the heart of Devitt's treatment do not necessarily clash with my view, since Devitt must be aware that his proposal is based on heavy contextual assumptions. What, nevertheless, I would like to stress is that Devitt's treatment does not do justice to the standard pragmatic interpretation of belief reports. After all, the use in (25) is not perceived to be the normal, ordinary use of belief reports, which is to throw light on the mental life of the believers. Why do we use the verb 'believe' in examples such as 'John believes that Mary is in Paris?". The semantics of the verb 'believe' is connected with the basic point of the statement made. What do we want to talk about when we use the verb believe? Presumably we want to talk about the believer's state, we want to say what it is roughly like, and if some details are missing these should be recovered by pragmatic processes which are in line with the basic point of using a belief attribution, that is to talk about the mental life of the believer. Contextual factors may lead us away from the believer's perspective, but it is not unreasonable to claim that the basic point of a belief report is to focus on the believer's perspective, thus constraining pragmatic processes which aim to fill in specific details into propositional schemas. That cases like the ones discussed by Devitt occur in ordinary conversation is something that must be taken into account, but while I do not wish to say that these cases are abnormal (in that almost nothing of what happens in conversation is abnormal), I claim that these examples are not basic, they are not the basis on which we should build up a theory of propositional attitudes. They are at most cases to be accounted for, as when the speaker's (or hearer's) perspectives clash pragmatic defaults are overridden by contextual information.

One might object to this and say that the use of belief reports to throw light on the mental life of believers is only one of their normal uses. Another is that we refer to what people believe in order to provide evidence for various claims, as in, "John thinks that $N$ is pretty (and since we all know that he has good taste)..." Here the issue is not whether John thinks of $N$ under the guise ' $N$ ' but rather choosing an NP that our *addressee* will easily process.

Well, this possible objection is based on a case in which a belief state is used to promote a certain inference (to lead the hearer, whoever she is, to a certain conclusion). We grant that human beings, with a few exceptions, are fundamentally rational and on the basis of their beliefs we form ourselves a number of further beliefs. This line of reasoning, however, must take into account the phenomenon of scalar implicatures: if A says " $X$ believes that $P$ ", she implicates that it may be the case that $X$ does not know that $P$. Why do these scalar implicatures arise? They do arise, presumably, because the lexical element 'believe' focuses on the believer's mental life. It is not in the basic cases, but with the intervention of rational thinking, that we can extract from $X$ 's beliefs further beliefs which we can accept. In other words, we need further premises, in addition 
to the fact that $X$ believes $P$, to arrive at further inferences about the way the world (external to $X$ 's beliefs) is.

There is one more thing to be added. In the sentence (33), there is an implicit mode of presentation which I marked as 0 , which is bound (through pragmatic anaphora) to the NP 'Mary Smith' in (25). This is not to suggest that there is always this implicit mode of presentation in the structure of the explicated thought, yet an array of implicit contextual assumptions may make the interpretation of this 0 as a neutral (and inert) mode of presentation under which the belief is held by the believer.

To consider an example adapted from Devitt (1996), suppose that my cousin, Robert McKay, has recently murdered John Gruff. I know that he is the murderer (furthermore suppose that he always tells me what he does). We happen to read the local newspaper, which has published an interview with an important detective, Sherlock Holmes. The detective provides some details about the state of the investigation and says that he is far from knowing the identity of the murderer. Among the things Sherlock Holmes says is that he believes that the murderer is insane. So both my cousin and I know that Sherlock Holmes is far from knowing the name of the murderer. Yet, I say:

Sherlock Holmes believes that the murderer is insane. Thus, Sherlock Holmes believes that [Robert McKay] 0 is insane

where 'Robert McKay' is the mode of presentation adopted to make Sherlock Holmes's belief relevant to the hearer and to induce him/her to reflect on his mental state and 0 is the mode of presentation under which the belief is originally held by the believer.

That contextual assumptions must be taken into account in pragmatic interpretations is well known. I do not take these as fatal objections to my relevance-theoretic treatment of belief reports. Green (1998), instead, believes that cases such as the one by Devitt militate against a pragmatic analysis of belief reports, presumably because he would like to align inferences such as the ones arising from belief reports to almost-universal implicatures such as those arising from utterances of "I lost a contact lens". Green argues that the implicature "I lost my contact lens" falls under the scope of negation and of modal embedding (conditionals) and, thus, is an ideal candidate for inclusion in "what is said" by a speaker. Implicatures from belief reports lack the almost-universal feature, presumably because they are defeated in some contexts. Well, I do not deny that certain contexts display features which defeat the ordinary inferences arising from belief reports, yet I would like to see them as special cases.

Devitt's (1996) approach may be seen as an ideal candidate for the treatment of belief reports presumably because it has the merit of reconciling Millian with Fregean theories (Davis, 2005). Yet, the approach is unsatisfactory because it does not address semantic and syntactic problems properly. The way Devitt hopes to reconcile both positions is to say that each NP (or AP) within the clause embedded in a belief verb expresses both a referent and a mode of presentation. Yet this apparently conciliatory move does not take into account the syntactic difficulties which were a threat to Schiffer's theory. Surely Devitt would not want to say that each NP (or AP) semantically expresses both a referent and a mode of presentation. Such a claim, even if possibly true, does not explain the opacity problem: the fact that belief contexts block the application of Leibniz's law. Consider Leibniz' Law: If $x$ is identical with $y$, whatever holds of $x$ holds of $y$ too (Williamson, 2000:33). Arguing in favour of the (semantic) association of every NP with a referent and a mode of presentation would ipso facto create a 
problem in that Leibniz's law would then be inapplicable even in the case of NPs outside the scope of belief-like operators (opacity would be exported outside the scope of belief verbs); not to mention the fact that not all NPs can be directly associated with referents (what about 'beauty', 'wealth', 'justice'?).

An additional problem is that, in the spirit of his conciliatory proposal, Devitt grants that both transparent and opaque interpretations are licensed by belief reports. He grants that a sentence such as (27):

\section{Ralph believes that Ortcutt is a spy}

has got the two following interpretations:

Ralph believes of Ortcutt that he is a spy;

Ralph believes that (assents to) "Ortcutt is a spy".

(28) constitutes the transparent construal, whereas (29) constitutes the opaque construal.A thorny problem for Devitt is that, everything being equal, a univocal semantic representation should be preferred to the ambiguity view, on grounds of parsimony (Modified Occam's Razor; see also the important work by Jaszczolt, 1999, who tries to eliminate ambiguities in favour of univocal interpretations). Another problem would be that the transparent reading, given his general conciliatory strategy of associating an NP both with a referent and with a mode of presentation, should be obtained by suppressing the mode of presentation the referent is associated with. So, Devitt faces the hard task of explaining where the mode of presentation comes from (semantically) in the opaque construal; in addition, he must explain how the mode of presentation is suppressed in the transparent construal. The move of resorting to the context of utterance is not allowed him, if his strategy is not pragmatic, but merely semantic. His strategy is clearly not pragmatic, given what he says, because he invokes no pragmatic machinery to explain what he assumes. Explaining in semantic terms how a mode of presentation within the scope of 'believe' is associated with an NP involves syntactically deriving the mode of presentation from the belief verb and claiming that it is an argument of the verb. But this move is not devoid of problems, as Schiffer and Recanati convincingly noticed.

A pragmatic approach avoids the proliferation of senses (or the ambiguity problem) and also explains why in some contexts, but not in others, modes of presentation are suppressed. It also explains why the opacity construals are default, ${ }^{3}$ by appealing to the notion of optimal relevance. The transparent interpretation is simply achieved by preventing a mode of presentation from arising, and thus needs a context in which the suppression of the mode of presentation is mandated by background knowledge. I also want to consider that the suppression of a mode of presentation should not be considered as a case of defeasibility. Explicatures are derived/ constructed through unreflective pragmatic mechanisms that promote the most relevant interpretation. Now it is true that if the NP in the that-clause of the belief report is not used to attribute a MoP to the believer, greater processing efforts are involved, but these are offset by the fact that an interpretation reducing the possibility of mistaken action has greater contextual effects. This is why the believer's MoPs are prevented from arising in certain cases in which

\footnotetext{
${ }^{3}$ I am not arguing that the inferences in question are the result of default rules, but only that they standardly get through.
} 
there is a heavy emphasis on the facilitation of action (presumably in Devitt's cases discussed above).

\section{Further considerations on null appositives}

What I have so far proposed is that pragmatic intrusion provides a specific mode of presentation, while I have suggested that there is a constituent present in the structure of the explicature, which has the features of a pronominal or a free variable and is a (pragmatic) empty category, in that it does not receive a phonological representation. This is a null appositive (it should be clear, however, that I am not proposing that the variable is present at LF). The possibility of an NP's having an appositive is exemplified by sentences such as (30):

$$
\text { Mary, the President of our union, is clever. }
$$

An appositive is surely a modifier, in that it adds further qualifications or restrictions to those expressed by the main NP. The appositive adds a superior node to an NP node, a node which has similar features, thus an NP. Of course, it is important to know whether the appositive adds a further constituent to the main proposition actually expressed by the sentence. The answer is in the positive since it is claimed that a MoP is part of the explicature and of the truth-conditions. Given that, in our belief sentences, the appositive representing a mode of presentation is a null element, we can represent it in this way:

John believes that [NP [NP Mary] [NP 0]] is clever.

A problematic task is to specify what this structure belongs to. Does it belong to the sentence? Or to the utterance? I thought that the least problematic answer is that the implicit appositive occurs as a pragmatic increment, thus at the level of the utterance. Pragmatic increments, however, have got some structure, just in the same way as Bach's famous implicitures require some structure (consider e.g. "Nurofen is better", where the missing material is an implicit subsentential element with some syntactic structure). The possibility of adjoining appositives to NPs is inherent in syntactic rules and there is no harm if pragmatic increments exploit and follow syntactic rules. It is natural to expect that all pragmatic increments be consistent with grammatical rules and with the syntactic potentials of the sentences/logical forms which provide input to explicatures.

We also need to tell what the content of the null appositive is once the sentence is pragmatically fleshed out. I expect that the content is furnished if there is some pragmatic binding or link between the null appositive, which I represented graphically as 0, and the NP which is the subject (or object) of the clause embedded in the attitudinal verb. The linking process occurs due to the workings of the principle of relevance: an interpretation that requires less processing efforts than another will get through.

We need not represent a MoP as a variable which is present at logical form; in fact, I propose that the MoP is a pragmatic increment at the level of the explicated proposition. I often represent this null MoP as 0, without implying that it is a semantic variable present at logical form. By using the notation symbol 0 all I intend to say is that the appositive which furnishes the concept of a mode of presentation is not heard. I implicitly accept that the pragmatic process of completion comes in three stages: (a) furnishing an appositive; (b) identifying this appositive with a mode of presentation which is not yet specific; (c) identifying this mode of presentation with some NP 
present at surface structure (specifically the NP the 0 appositive is an appositive to). I can see no problem with this, as I avoid the assumption that 0 is a variable present at logical form. All I say is that pragmatics furnishes some constituent which I call 0 at the level of the propositional form; this 0 is an appositive to an NP (or VP); furthermore pragmatics ensures that this appositive is identical with some mode of presentation MoP and that the specific content of MoP is obtained by binding $0 / \mathrm{MoP}$ with some NP.

Another problem with my proposal is the following. It may be plausibly argued that a sentence such as (30) is truth-conditionally equivalent to (32):

Mary, who is the President of our union, is clever.

Now, suppose we embed this sentence into a belief report, we obtain:

John thinks that Mary, who is the President of our union, is clever.

On one interpretation the relative clause just gives more information about Mary without shedding light on how John thinks of her (see also Arnold, 2007:276). The objection is a natural one and a very good one too. The problem arises not really from implicit appositives, but from explicit ones, like the ones above, which can be understood ' $d e$ re'. I attempt to resolve this problem in sections 6 and 7.

The discussion so far has hinged on the assumption that we can have something like null appositives, specifically modes of presentation, in the structure of NPs belonging to thatclauses embedded in verbs of belief. The literature on pragmatic intrusion is characterised by endless discussions on whether we should posit empty constituents in logical forms of sentences such as "It rains". Recanati (2004) is a champion of the view that we should not posit these empty categories at logical form. I must say, in the words of Mey (personal communication) that in cases such as the one discussed by Recanati there is not clear-cut evidence in favour of one or another theory. But have we got independent evidence for the existence of this null appositive that modifies NPs within the scope of belief verbs? I propose that we should set aside the task of assigning null appositives at logical form and remain content with stipulating that such appositives appear in the propositions expressed (so we are following Recanati, 2004 and Carston, 2002). Some crucial and indubitable evidence comes from sentences such as (34):

John believes that Mary Pope went to Paris and that she had fun.

I propose we should analyse (34) as providing evidence for a proposition such as

(35)John believes that [Mary Pope] 0 went to Paris and that [she] 0 had fun.

It is interesting to note that if we allow implicit modes of presentation, we have got a double anaphoric pattern, as the indexes show:

John believes that $[\text { Mary Pope }]_{i} 0_{n}$ went to Paris and that $[\mathrm{she}]_{i} 0_{n}$ had fun.

The subscript $i$ represents the reference of 'Mary Pope', and this is attributed through coindexation to 'she'. Instead, $n$ is the subscript attributed to 0 , the mode of presentation 
associated with 'Mary Pope' (which must be coindexed with the form 'Mary Pope'), and that is coindexed with the implicit mode of presentation 0 associated with 'she'. Notice that, unless we have got this (conceptual) anaphoric chain, which is possible only through the existence of null modes of presentation (or null appositives), it would be possible to understand (36) allowing 'she' to be intersubstitutable with any NP at all that has the same referent as 'Mary Pope', with no regard for the mode of presentation 'Mary Pope'. But this is not the natural interpretation of the utterance.

Further evidence comes from control structures:

John believes Mary Pope to be in Paris and [PRO]0 to be working hard (instead she is having fun with her other boyfriend).

The control structure ensures that the reference of 'Mary Pope' is transmitted through anaphora to PRO; however unless we posit that PRO has got a null appositive in the explicature, we cannot account for the opacity of the structure, as certainly by replacing PRO with an NP coreferential with 'Mary Pope' (but distinct from it) a statement having different truth-conditions may be obtained. ${ }^{4}$

A more interesting piece of evidence comes from Italian control structures:

Maria crede di PRO essere intelligente.

(lit. Maria believes PRO to be intelligent)

Maria believes she is intelligent.

Suppose we call Maria 'Maria', but she does not know that this is her name; in fact, she does not know that she has a name. Maria thinks of herself under some mode of presentation of the self (a first-person mode of presentation), but this does not include the name 'Maria', which, instead, is the mode of presentation we associate with her. This case strongly supports the idea that we must posit a propositional structure such as the following:

Maria crede di [PRO] 0 essere intelligente.

In fact, while PRO in the present case receives its reference through an anaphoric link with Maria, it cannot be associated with the mode of presentation 'Maria'. We thus need a way of signalling that PRO must be possibly distinct from 0 and that 0 must be possibly distinct from 'Maria'. 0 is associated with PRO, but not through anaphora, only as a null appositive, which is capable of having the meaning of 'whatever coincides with the subject of belief' ${ }^{5}$ This is what Lewis (1979) calls an attitude 'de se'. Higginbotham's (2004) considerations on the "internal" aspect of PRO (in the context of a discussion of 'de se' beliefs) are applicable here: what is believed by Maria to be intelligent is the subject of the experience BELIEVING (see also Stanley and Williamson, 2001, for an analogous view). The example (47) is reminiscent of Castañeda's (1966) famous example "The editor of Soul knows that he is a millionaire". This, according to Castañeda, does not entail that the Editor of Soul knows that the Editor of Soul is a millionaire.

Further evidence comes from verbs of propositional attitude like 'want', which mandate control structures. Consider (40):

\footnotetext{
${ }^{4}$ In this respect, my view is different from Salmon's.

${ }^{5}$ My example is reminiscent of an example by Stanley and Williamson (2001), who actually use a case of amnesia to exemplify de se interpretations.
} 
Suppose Mary is not aware that Cicero is Tullius; she would like Cicero to come to the party, but she would like Tullius not to come to her party (say she has always heard nice things about Cicero but bad things about Tullius). If she knew that Cicero is Tullius, she would not let him come. (40) ought to be analysed as (41):

Mary wants Cicero [ti 0 to come to the party] but she does not want Tullius [tii 0 to come to the party]. ${ }^{6}$ Unless we posit null appositive modes of presentation associated with ti and ti, the sentence (40) has to be perceived as a contradiction, since ti inherits its reference from 'Cicero', tii inherits its reference from 'Tullius' (in conjunction with the premise that Cicero $=$ Tullius). However, the sentence is not contradictory because Mary, due to her frame of mind, will not admit Tullius to her party (given the bad things she has heard about him), but she will allow Cicero (given the nice things she has heard about him). The sentence (40) reminds us of Cohen's famous example (Cohen, 1971):

If the king of France dies and France becomes a republic, I shall be happy, but if France becomes a republic and the king of France dies I shall be unhappy.

The sentence (42) has an appearance of contradiction, unless we furnish the explicatures and provide a temporal and causal interpretation for the material in each if-clause. When the interpretative ambiguity is resolved, we no longer face a possibly contradictory sentence (however, see Capone, 2006a for a more detailed proposal, in addition to Burton-Roberts, 2005). Analogously, by furnishing the explicature of (42) and in particular by coindexing each 0 (implicit mode of presentation) with the NP 0 is an appositive to, we obtain a statement which is no longer contradictory.

A further example that can be used to prove that implicit modes of presentation do some work at the propositional level is drawn from Seymour's (1992) paper. Seymour defends a sentential theory of propositional attitudes and essentially believes that a person $X$ believes that $S$ in case he is in a relation $R$ to a certain sentence. If we mention the sentence in order to specify its character, the whole belief sentence reports a belief relation between the agent and a certain linguistic meaning under a mode of presentation that is a certain verbal form. If we mention the subordinate clause in order to specify its content, the agent is then described as being in a relation with the content of the sentence mentioned and, in this case, the sentence no longer behaves as a mode of presentation. Seymour calls the first type of belief intentional belief and the second material belief. Seymour considers that intentional beliefs (opaque readings) are distinguished by the fact that they are reflexive. Material beliefs are distinguished by the fact that they are not reflexive. Thus, if (43) is true, (44) must be true, provided that we consider the opaque reading of (54):

John believes that Mary Simpson went to Paris.

John believes he believes that Mary Simpson went to Paris.

If John is not ready to assent to 'Mary Simpson went to Paris', there is no way to derive the inference (44). Seymour's intuition is most easily explained away by resorting to modes of presentation (given Kripke's reasonable doubts about the equation of believing and assenting to a proposition). Thus the statement or thought (43) must receive an adequate representation as (45):

\footnotetext{
${ }^{6}$ I am adopting this analysis from Carnie (2002).
} 
where 0 represents the null appositive or mode of presentation, which is coindexed with the form 'Mary Simpson'.

Williamson (2006) says that there is the case in which John lacks self-knowledge or does not grasp the concept of belief. Presumably this amounts to an objection against my treatment. As a reply, I must consider that in some cases the reflexivity of belief (or of knowledge) comes to the philosopher's help in resolving otherwise insuperable problems. Stanley and Williamson's (2001) discussion of opacity in favour of the idea that knowledge-how is a sub-species of knowledge-that is one such case. Of course, if knowledge-that involved opacity while knowledge-how involved a transparent relation to an embedded proposition $p$, there would be serious trouble for Stanley and Williamson who have taken great pains to analyse knowledgehow in terms of a relation between a (cognitive) agent and a proposition (invoking the semantic machinery of embedded questions). In particular, there would be trouble if there was no significant truth-conditional difference between "Hannah knows how to locate Hesperus" and "Hannah knows how to locate Phosphorus". Stanley and Williamson claim that the latter proposition does not seem to follow from the former. But their analysis tacitly assumes that knowledge is a reflexive relation. Only reflexivity can block the intersubstitution of the two names, because despite the fact that Hannah is able to locate on a map (of the universe) that planet there in the sky regardless of its name(s) (and thus in a sense she is able to locate both hesperus and phosphorus), she would not say of herself that she knows she knows how to locate phosphorus even if she knows she knows how to locate Hesperus. As Seymour would say, it is the reflexive notion of knowledge-how that blocks substitution.

Independent evidence in favour of the presence of modes of presentation of the referent in that-clauses of belief reports comes from what Stanley (2005) says about ellipsis. Stanley argues that explicatures enter into certain linguistic processes such as anaphora and deixis (this is well known since Chomsky, 1972:33). An example such as (46):

The ham sandwich wants his bill now

proves that the pragmatic determination of the referent of 'The ham sandwich' (the person who ordered the ham sandwich) must be available for anaphoric coindexation. The examples of ellipsis are even more interesting. Consider (47):

Bill served a ham sandwich, and John did too.

(47) cannot be interpreted as conveying that Bill served a person who ordered a ham sandwich, whereas John served a ham sandwich. The explicature of the first conjunct of (47) must be available for the understanding of the elided constituent too. In other words it must be used in providing an explicature that reconstructs the missing (elided) constituent.

Analogous considerations apply to metaphorical meaning, which is carried over in ellipsis, showing that explicatures play a role in this linguistic process:

John is a pig and Bill is too.

Now, let us apply ellipsis to belief reports. Consider:

John believes that Kent Clark is not Superman and Fred does too. 
We said above that ellipsis carries over the explicature of the first sentence to the elided constituent. Thus, it is not licit to interpret (49) as the thought that John believes a non-contradictory thought while Fred believes a contradictory one. In other words, it is not licit to replace 'Kent Clark' with 'Superman' in the elided constituent, as a result of a syntactic constraint due to ellipsis: the explicature of the first sentence must be used in reconstructing the meaning of the elided constituent (we could also use talk of a 'parallel' explicature). What is this explicature? I assume that it consists in the attribution of the mode of presentation 'Kent Clark' to the referent Kent Clark.

Analogous considerations apply to (50) (to use comparatives, which were first taken account of by Carston in her discussion of the semantics/pragmatics debate):

John believes that Kent Clark is better than Superman and Fred does too.

As Carston (2002) and Levinson (2000) noted, the statement 'A is better than B' presupposes that $\mathrm{A}$ and $\mathrm{B}$ are distinct, otherwise it communicates a patently false thought.

Ellipsis in (50) imposes the constraint that the explicature of the first conjoined sentence should carry over to the elided constituent. In particular, the elided constituent cannot be interpreted as "Fred holds the belief that Kent Clark is better than himself". What is it that blocks substitution 'salva veritate' in the elided constituent? Presumably it is the fact that 'Kent Clark is associated with the mode of presentation 'Kent Clark' in the explicature of the first conjunct and it cannot be associated with the mode of presentation 'Superman' in the explicature of the second conjunct. This is best explained away on the assumption that the explicature of the first conjunct is that Kent Clark is associated with the MoP 'Kent Clark' in John's belief and that there is a linguistic constraint due to ellipsis such that the explicature of the first conjunct is carried over to the elided constituent of the second conjunct.

\section{An alternative analysis}

So far, I have developed an analysis following Bach's idea that one should posit null appositives (not in the logical form, but) at the level of the propositional form. I have also elaborated on the reasons why null appositives are required at the level of the propositional form. Yet, I am not exempted from providing a semantic analysis of the propositional form thus obtained through pragmatic expansion. Furthermore, it is possible that the ideas exposed so far may be further expanded so as accommodate a plausible objection. Presumably a semantic analysis of the propositional development of null appositive clauses looks like this:

$$
\text { John believes that [NP } 0 \mathrm{VP}]
$$

where 0 is a null appositive (presumably an NP). This is in line with Del Gobbo's (2003) idea that appositives expand NPs into NPs (through adjunction). If we adopt the idea that a null appositive is nothing but a relative clause, then we have a further expansion of the structure above:

John believes that $[\mathrm{NP}[\mathrm{CP}$ who $[t$ is NP]] VP]

where $t$ is the trace of the relative pronoun which moves to a node dominated by CP (complementizer phrase) (see Haegeman, 1994).

A plausible consequence of this analysis is that the null relative clauses may be taken as providing the speaker's mode of presentation of the reference (in addition to the believer's mode 
of presentation of the reference). In response to this possible problem, something else must be said about a sentence such as "John believes that Mary went to Paris".

I now propose to take advantage of my considerations in Capone (2000). There, I proposed that clitics in clitic-doubling constructions qualify propositions believed or known in a special way, anchoring them to discourse. While I recognize that more than one view is tenable in connection with the Italian clitic 'lo', I now think that a theory along the lines I have just proposed is not untenable. Consider (53):

Giovanni lo sa che Maria è a Parigi.

(lit. Giovanni it knows that Mary is in Paris)

(Giovanni knows that Mary is in Paris).

The clitic 'lo' qualifies the proposition known as being part of shared knowledge. It is possible to waver between a semantic and a pragmatic analysis, but this is not important for the present paper, as the semantic analysis may be seen as deriving diachronically from the pragmatic analysis. In any case, both Uriagereka (1995) and Capone (2000) have claimed that the clitic has the effect of qualifying the that-clause embedded in the verb of propositional attitude as being part of the commonground. Yet Uriagereka claims that the that-clause is an appositive to the clitic, the clitic functioning as an argument to the verb. This view is not implausible. Suppose, however, that we reverse this view and claim that the clitic is an appositive to the that-clause. In this way we obtain an analysis parallel to the one I have proposed for verbs of propositional attitude in general. Modes of presentations are appositives. In the case of clitics (in cliticdoubling constructions), they are pronominal appositives, which qualify a proposition in a certain way: they can function as words that imply certain modes of presentation. Of course, they need not be called modes of presentation, except in a special sense. The word 'lo' qualifies the embedded proposition (in clitic doubling constructions) as part of the commonground, but the word itself is not the mode of presentation of the embedded proposition. It implies a mode of presentation.

Suppose that we exploit the intuitions about the role of clitics in clitic-doubling constructions (e.g. "Giovanni lo sa che $p$ " (Giovanni it knows that $p$ )). We said that the clitic is mainly an appositive (reversing Uriagereka's analysis according to which the clitic was the complement of the attitudinative and the proposition $p$ an appositive). Furthermore suppose that all attitudinatives have got a null appositive similar in semantic/syntactic structure to the clitic, but syntactically different in that it has got an internal articulation of the type:

$[\mathrm{MoP} / \mathrm{SN}, \mathrm{MoP} / \mathrm{VP}]$,

where by MoP we indicate a mode of presentation. We also suppose that this supposition can be held cross-linguistically (unless there is evidence that a language has got a different structure; we are open to the hypothesis that languages may vary according to whether they exhibit tacit or otherwise explicit appositive clauses to attitudinatives).

Well, at this point all attitudinatives have got the following semantic/syntactic structure:

$$
\text { John believes [[that } P][\text { NPMoP VPMoP]] }
$$

It is not surprising that there are appositives to sentences, given that sentential arguments are assimilated to NPs. In any case, De Vries (2002) provides a number of examples of appositives to 
sentences. Given this semantic structure, relevance theory intervenes to supply appropriate binding between NPMoP and the NP occurring in $P$.

It may be objected that this alternative analysis places a greater load on the semantics, than on the pragmatics. Yet, we still have to posit appositives to explain the behaviour of clitic-doubling in languages like Italian and to posit null appositives for English is no costly move, given that appositives exist in English and thus the English language must have the semantic and syntactic resources for expressing them.

It may take time to adjudicate between the previous position and the one I express in this section. It is not clear to me that the null appositive view, as I expressed it, requires positing free variables (of a complex kind) at Logical Form, in the sense of Stanley (2000), in which case pragmatics is assigned the modest role of filling in these variables, of giving them semantic values by saturating them. The picture I have so far provided is compatible with a full pragmatic intrusion story. The syntactic structure of the null appositive to the embedded clause of a belief report is just the structure of a constituent we mentally supply through pragmatics and it is possibly not part of the semantic structure of a belief sentence.

At this point, we have to clear out how we should treat clitic doubling with verbs of propositional attitude. Supposedly, they have a structure similar to the constructions where no clitic appears, with the difference that the clitic is already there, and already functions as an apposition to the that-clause. However, there is nothing in the grammar that banishes the idea of having cyclic appositives (or reiterated appositives), an appositive being an appositive to another appositive. At this point, we can assign the following structure to clitic doubling constructions such as "Giovanni lo sa che $p$ ":

$$
\text { Giovanni sa [[che } S] \text { [[NP lo] [NP/MoP, VP/MoP]]] }
$$

This enables the clitic to provide, by semantic implication, a mode of presentation of the whole of $S$, while [NP/MoP, VP/MoP] supplies a structure which is more articulated and provides null modes of presentation which can be bound with NPs within the embedded clause. We can think of these MoPs as present in constituents we assign the sentence through pragmatics. The present analysis assumes, in line with De Vries (2002) and Arnold (2007), that appositives can be stacked in English and in many other languages (an English example is "This man, who came to dinner late, about whom nobody knew anything...”).

\section{Conclusion}

In this paper I have tried to connect two issues which are usually dealt with separately: belief reports and pragmatic intrusion (the semantics/pragmatics debate). I have proposed that advances in the former issue cannot be made without advances in the latter. The semantics of a sentence is often too skeletal to accommodate all the elements of a thought; thus pragmatics must contribute to the expression of implicit constituents. Modes of presentation are usually contributed to a thought through pragmatics. In this paper I explored and extended an important idea by Bach (2000). Bach says that even though 'that'-clauses express propositions, belief reports do not in general specify things that people believe (or disbelieve) - they merely describe or characterize them (Bach, 2000:121). In this article pragmatics has been shown to play an important role in specifying the things people believe. The contribution of this paper was to explain, through relevance theory, that a belief report opens a window on the mental 
panorama of a believer and focuses on his way of representing constituents of thought. I explained that in examples such as

John believes that Mary Smith is clever

the sentence is optimally relevant if the NP 'Mary Smith' is the mode of presentation associated (pragmatically) with the referent of 'Mary Smith', in other words if it plays some role in the identification of reference for the believer. Given that relevance is a ratio of contextual effects and cognitive efforts, it goes without saying that either cognitive efforts or cognitive efforts play a role in the calculation of relevance. I proposed that the interpretation that is most relevant is the one in which the MoP 'Mary Smith' is actually used by the believer in identifying the referent in question given that selecting different NPs as potential modes of presentation would require greater processing efforts. Only in cases in which these further processing costs are offset by further contextual effects is it plausible to deviate from this standard interpretation process.

An important point of this paper was to propose that a sentence with a belief-like predicate is normally to be analyzed as

$$
\text { John believes [[that } P][\text { NPMoP VPMoP]]. }
$$

In this way one can easily explain the intuition that non-restrictive relative clauses actually express a speaker's mode of presentation (rather than a believer's mode of presentation). This may be explained by the fact that non-restrictive clauses attach to NPs, while the modes of presentation of embedded propositions are appositions at the level of sentences. Presumably it is the semantics of non-restrictive relative clauses that forces interpretations according to which they express a speaker's and not a believer's mode of presentation. This is not to say that this is the last word on the issue. De Vries (personal communication), in fact, has voiced a number of objections, which, I think, can be disposed of. He says:

If I am not mistaken, appositives to clauses are also speaker-oriented. E.g., "John fell from the roof, which was hilarious". This is a qualification by the speaker. I hope this is not a problem for your theory.

De Vries is certainly right, but we are obviously interested in belief contexts. So see what happens in a belief context:

John believed that Mary is mad, which is hilarious.

It appears to me that what is hilarious is the belief, not the fact that Mary is mad. Also note that we can have the same effect with factive and reporting verbs, as in (59) and (60), where the appositive refers to the main predicate (notice/say):

John finally noticed that Mary was angry, which was hilarious.

John said that Mary was angry, which was hilarious.

De Vries, however, adds that in other contexts, the appositive may refer to the embedded clause:

(3) John believes/says that Mary is crazy, which I doubt. 
This does not worry me. In fact, consider (61) and (62):

(61) John believes/says that Mary is crazy, which he may doubt in the future.

(62) John believes that Mary is crazy, which he really believes.

In (61) and (62) the sentential appositive expresses the perspective of the believer. At most one can say that sentential appositives can express both the speaker's and the believer's point of view. This view fits in with a pragmatic analysis in which contextual elements or default reasonings promote the believer's mode of presentation. In other words, pragmatics will disambiguate and will provide an interpretation of the null appositive such that it will furnish the believer's mode of presentation.

\section{Acknowledgements}

Thanks God, I have been able to bring this paper to completion. I would like to give thanks to Jacob L. Mey whose comments, encouragement and positive scholarly attitude have led me to greater intellectual maturity. Words to do not suffice to express my gratitude for his ever-lasting encouragement: I will always jealously keep the memory of what he has done for me in my heart. Thanks to Yan Huang and James Higginbotham, who were able to appreciate these ideas when they were still in an embryonic state. Thanks to Mark De Vries for his illuminating comments. I am extremely grateful to Deirdre Wilson and Robyn Carston. M. Seymour generously offered many comments. I would also like to express my thanks to Timothy Williamson, who read this manuscript carefully and provided a number of constructive comments, allowing me to eliminate errors. He has enabled me to improve my mind enormously. I am very grateful to three anonymous referees for helping me prune all excesses and provide a much clearer text. They made me reflect on a number of important issues. They also allowed me to eliminate a number of errors. Much of what is good in this paper is the result of their zealous thought-provoking comments.

\section{References}

Arnold, Doug, 2007. Non-restrictive relatives are not orphans. Journal of Linguistics 43, 271-309.

Bach, Kent, 1994. Conversational impliciture. Mind and Language 9, 124-162.

Bach, Kent, 2000. Do belief reports report beliefs? In: Jasczolt, K. (Ed.), The Pragmatics of Propositional Attitude Reports. Elsevier, Oxford, pp. 111-136.

Bezuidenhout, Ann, 2000. Attitude ascriptions, context and interpretative resemblance. In: Jaszczolt, K. (Ed.), The Pragmatics of Propositional Attitude Reports. Elsevier, Oxford, pp. 137-168.

Burton-Roberts, Noel, 2005. Robyn Carston on semantics, pragmatics, and 'encoding'. Journal of Linguistics 41, 389407.

Burton-Roberts, Noel, 2006. Cancellation and intention. Newcastle working papers in linguistics 12-13, 1-12.

Capone, Alessandro, 2000. Dilemmas and Excogitations: An Essay on Modality, Clitics and Discourse. Messina, Armando Siciliano.

Capone, Alessandro, 2006a. On Grice's circle: further consideration on the semantics/pragmatics debate. Journal of Pragmatics 38, 645-669.

Carnie, Andrew, 2002. Syntax. A Generative Introduction. Blackwell, Oxford.

Carston, Robyn, 1999. The semantics/pragmatics distinction. In: Turner, K. (Ed.), The Semantics/Pragmatics Interface from Different Points of View. Elsevier, Oxford, pp. 85-125.

Carston, Robyn, 2002. Thoughts and Utterances. The Pragmatics of Explicit Communication. Blackwell, Oxford.

Castañeda, Hecor-Neri, 1966. He*: a study in the logic of self-consciousness. Ratio 8, 130-157.

Chomsky, Noam, 1972. Language and Mind. Harcourt Brace Jovanovich, New York. 
Cohen, L.J., 1971. Some remarks on Grice's views about the logical particles of natural language. In: Bar-Hillel, Y. (Ed.), Pragmatics of Natural Language. Reidel, Dordrecht, pp. 50-68.

Crimmins, Mark, Perry, John, 1989. The prince and the phone booth: reporting puzzling beliefs. The Journal of Philosophy 86, 685-711. Reprinted in: Ludlow, P. (Ed.), Readings in the Philosophy of Language. Cambridge, Ma, MIT Press, pp. 963-991.

Davis, Wayne, 2005. Non Descriptive Meaning and Reference. An Ideational Semantics. OUP, Oxford.

De Vries, Mark, 2002. The syntax of relativization. LOT, Utrecht.

Del Gobbo, Francesca, 2003. Appositives at the interface. Ph.D. Thesis, University of California, Irvine.

Devitt, Michael, 1996. Coming to Our Senses: A Naturalistic Program for Semantic Localism. CUP, Cambridge.

Green, Mitchell S., 1998. Direct reference and implicature. Philosophical Studies 91, 61-90.

Haegeman, Liliane, 1994. Introduction to Government and Binding Theory. Blackwell, Oxford.

Higginbotham, James, 2004. Remembering, Imagining, and the First Person. Manuscript. University of Southern California.

Jaszczolt, K., 1999. Discourse, Beliefs and Intentions. Elsevier, Oxford.

Kripke, Saul A., 1979. A puzzle about belief. In: Margalit, A. (Ed.), Meaning and Use. Dordrecht, Reidel, pp. $239-283$. Reprinted in Ludlow, P. (Ed.), 1997, Readings in the Philosophy of language. Cambridge, Ma, MIT Press.

Lewis, David, 1979. Attitudes de dicto and de se. The philosophical Review 88, 513-543.

Mey, Jacob L., 2001. Pragmatics. An Introduction 2nd Edition. Blackwell, Oxford.

Recanati, François, 2004. Literal Meaning. CUP, Cambridge.

Salmon, Nathan, 1986. Frege's Puzzle. MIT Press, Cambridge, MA.

Seymour, Michel, 1992. A sentential theory of propositional attitudes. The Journal of Philosophy 22, 181-201.

Sperber, Dan, Wilson, Deirdre, 1986. Relevance: Communication and Cognition. Oxford, Blackwell. Reprinted with postface in 1995.

Stainton, Robert J., 2004a. Quantifier phrases, meaningfulness “in isolation” and ellipsis. In: Davis, S., Gillon, B. (Eds.), Semantics. A reader. OUP, Oxford, pp. 846-865.

Stainton, Robert, 2004b. The pragmatics of non-sentences. In: Horn, L.R., Ward, G. (Eds.), The Handbook of Pragmatics. Blackwell, Oxford, pp. 266-286.

Stanley, Jason, 2005. Semantics in context. In: Preyer, Gerhard (Ed.), Contextualism. OUP, Oxford, pp. $221-254$.

Stanley, Jason, Williamson, Timothy, 2001. Knowing how. Journal of Philosophy 98/8 .

Uriagereka, J., 1995. Aspects of the syntax of clitic placement in Romance. Linguistic Inquiry 26, 79-123.

Williamson, Timothy, 2000. Knowledge and its Limits. OUP, Oxford.

Williamson, Timothy, 2006. Comments on Capone's paper 'Belief reports and pragmatic intrusion: the case of null appositives, MN.

Wilson, Deirdre, Sperber, Dan, 2002. Truthfulness and relevance. Mind 111, 583-632.

\section{Further reading}

Asher, Nicholas, 2000. Events, facts, propositions, and evolutive anaphora. In: Higginbotham, J., Pianesi, F., Varzi, A.C. (Eds.), Speaking of Events. OUP, Oxford, pp. 123-150.

Barwise, J., Perry, John, 1981. Semantic innocence and uncompromising situations. Midwest Studies in Philosophy 6, 387-403.

Berg, Jonathan, 1988. The pragmatics of substitutivity. Linguistics \& Philosophy 11, 355-370.

Blakemore, Diane, 2000. Indicators and procedures: nevertheless and but. Journal of Linguistics 36, 463-486.

Blakemore, Diane, Carston, Robyn, 2005. The pragmatics of sentential coordination with 'and'. Lingua 115/4, 569-589.

Braun, David, 1998. Understanding belief reports. Philosophical Review 105, 555-595.

Burton-Roberts, Noel, 1994. Ambiguity, sentence and utterance: a representational approach. Transactions of the Philological Society 92/2, 179-212.

Burton-Roberts, Noel, 2007. Varieties of asemantics and encoding: negation, narrowing/loosening and numericals. In: Burton-Roberts, N. (Ed.), Pragmatics, Palgrave-Macmillan, London, pp. 90-114.

Capone, Alessandro, 1998. Modality and Discourse. Doctoral Dissertation. University of Oxford

Capone, Alessandro, 2001a. Modal Adverbs and Discourse. ETS, Pisa.

Capone, Alessandro, 2001b. Review of Levinson's 'presumptive meanings'. Language 77/3, 578-580.

Capone, Alessandro, 2003a. Tra Semantica e Pragmatica. Clueb, Bologna.

Capone, Alessandro, 2003b. Review of Jaszczolt's “The pragmatics of propositional attitude reports”. Lingua 113, 167172. 
Capone, Alessandro, 2004. Review of Carston's “Thoughts and utterances. The pragmatics of explicit communication” Linguistics 42/6, 1185-1189.

Capone, Alessandro, 2005a. Review of Recanati’s “Literal Meaning”. Journal of Linguistics 41, 44-49.

Capone, Alessandro, 2005b. On the social practice of indirect reports. www.semanticsarchive.net.

Capone, Alessandro, 2006b. Are explicatures cancellable? Manuscript.

Capone, Alessandro, 2007. Review of Lepore \& Ludwig. Donald Davidson: meaning, truth, language and reality. Journal of Pragmatics 39, 1039-1046.

Cappelen, Herman, Lepore, Ernie, 2005. Insensitive Semantics: A Defence of Semantic Minimalism and Speech Act Pluralism. Blackwell, Oxford.

Cappelen, Herman, Lepore, Ernie, 2006a. The myth of unarticulated constituents. Rutgers University, MN.

Carston, Robyn, 2004. Relevance theory and the saying/implicating distinction. In: Horn, L.R., Ward, G. (Eds.), The Handbook of Pragmatics. Blackwell, Oxford, pp. 633-656.

Castañeda, Hector-Neri, 1967. Indicators and quasi indicators. American Philosophical Quarterly 4, 85-100.

Davidson, Donald, 1984. On saying that. In: Davidson, D. (Ed.), Inquiries into Truth and Interpretation. OUP, New York, pp. 93-108.

De Vries, Mark, 2006. The syntax of appositive relativization: on specifying coordination, false free relatives, and promotion. Linguistic Inquiry 32/2 .

Dummett, Michael, 1973. Frege Philosophy of Language. Harvard University Press, Cambridge, MA.

Forbes, Graeme, 1997. Belief reports and speech reports. In: Künne, W., Newen, A., Anduschus, M. (Eds.), Direct Reference, Indexicality, and Propositional Attitudes. CSLI, Stanford, pp. 313-330.

Jacob, Pierre, 1997. Frege's puzzle and belief ascriptions. In: Künne, W., Newen, A., Anduschus, M. (Eds.), Direct reference, Indexicality, and Propositional Attitudes. CSLI, Stanford, pp. 215-246.

Jaszczolt, K., 2005. Default Semantics. Foundations of a Compositional Theory of Acts of Communication. OUP, Oxford.

Levinson, S.C., 1983. Pragmatics. CUP, Cambridge.

Quine, W.V., 1960. Word and Object. MIT Press, Cambridge, MA.

Recanati, François, 1993. Direct Reference. From Language to Thought. Blackwell, Oxford.

Richard, Mark, 1983. Direct reference and ascriptions of belief. Journal of Philosophical Logic XII, 425-452.

Salmon, Nathan, 1990. A Millian heir rejects the wages of sinn. In: Anderson, Anthony C., Owens, Joseph (Eds.), Propositional Attitudes. The Role of Content in Logic, Language, and Mind. CSLI Publications, Stanford, pp. 215248.

Schiffer, Stephen, 1995. Descriptions, indexicals, and belief reports: some dilemmas (but not the ones you expect). Mind vol. 104/413, 107.131. Reprinted in: Künne, W., Newen, A., Anduschus, M. (Eds.), Direct reference, indexicality and propositional attitudes. Stanford, CSLI, pp. 247-275.

Schiffer, Stephen, 2000. Propositional attitudes in direct-reference semantics. In: Jaszczolt, Katarzyna (Ed.), The Pragmatics of Propositional Attitude Reports. Elsevier, Oxford, pp. 14-30.

Sperber, Dan, 1997. Intuitive and reflective beliefs. Mind and Language 12/1, 67-83.

Sperber, Dan, Wilson, Deirdre, 2007. Pragmatics. In: Jackson, F. and Smith, M. (Eds.), 2005 Oxford handbook of analytic philosophy. Oxford, OUP, pp. 468-501.

Wilson, Deirdre, 1998a. Discourse, coherence, and relevance: a reply to Rachel Giora. Journal of Pragmatics 29, 57-74.

Wilson, Deirdre, 1998b. Linguistic structure and inferential communication. In: Caron, B. (Ed.), Proceedings of the 16th International Congress of Linguists, Paris, July 20-25, 1997, Elsevier, Oxford.

Wilson, Deirdre, 2000. Metarepresentation in linguistic communication. In: Sperber, D. (Ed.), Metarepresentations: A Multidisciplinary Perspective. OUP, Oxford, pp. 411-448.

Wilson, Deirdre, 2003. Relevance and lexical pragmatics. Italian Journal of Linguistics 15 (2), $273-291$.

Wilson, Deirdre, 2005. New directions for research on pragmatics and modularity. Lingua 105, 1129-1146.

Wilson, Deirdre, Sperber, Dan, 1993. Linguistic form and relevance. Lingua 90, 1-25.

Wilson, Deirdre, Sperber, Dan, 2004. Relevance theory. In: Horn, L.R., Ward, G. (Eds.), The Handbook of Pragmatics. Blackwell, Oxford, pp. 607-632.

\footnotetext{
Alessandro Capone obtained a doctorate from the University of Oxford in 1998, supervised by Prof. Yan Huang and examined by James Higginbotham and Sally McConnell-Ginet. Dr. Capone carried out post-doctoral research at the University of Messina. Then he taught there applied linguistics. Subsequently, he has carried out pure research at the University of Palermo in the Philosophy Department.
} 